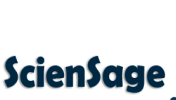

Journal of Advanced Scientific Research

Available online through https: / /sciensage.info
ISSN: 0976-9595

Research Article

DOI: $10.55218 /$ JASR. 202213141

\title{
ANTIOXIDANT ENZYME ACTIVITY OF SHATHAVARIN- IV IN DROSOPHILA MELANOGASTER UNDER OXIDATIVE STRESS
}

\author{
Kiran Kumar K.V., Ashadevi J.S.* \\ Genetics Research Laboratory, Department of Zoology, Yuvaraja’s College, University of Mysore, Mysuru, Karnataka, India \\ *Corresponding author: Drosolabycm@gmail.com
}

\begin{abstract}
Shathavarin-IV is a bioactive compound (a steroidal saponin) of Asparagus racemosus. We examined the antioxidant effects of Shathavarin-IV associated with LPO in Drosophila. The antioxidant efficacy of the compound was evaluated through the determination of antioxidant enzymes such as superoxide dismutase (SOD), catalase (CAT), glucose-6-phosphate dehydrogenase $\left(\mathrm{G}_{6} \mathrm{PD}\right)$ and LPO in the homogenate of the Shathavari-IV supplemented flies of D. melanogaster under stressed and non-stressed conditions. The oxidative stress was induced by paraquat exposure. All the analyses were carried out in males and females at two different concentrations of Shr-IV $(1 \mathrm{mg} / \mathrm{ml}$ and $10 \mathrm{mg} / \mathrm{ml}$ of diet $)$ fed groups. The induced oxidative stress by paraquat exposure was evidenced by significant declining in the level of SOD, CAT and $\mathrm{G}_{6} \mathrm{PD}$ with the increase in the level of LPO. In case of dose-I and dose-II pretreated flies, a significant diminishes in the level of LPO with significant increase of antioxidant enzymes were observed. The compound Shr-IV exhibited better level of protective ability in high dose treatment against the stress compared to low dose.
\end{abstract}

Keywords: Shathavari-IV, Drosophila melanogaster, Oxidative stress, Paraquat, Antioxidant enzymes.

\section{INTRODUCTION}

Generally free radicals are compensated within our body by the endogenous antioxidant systems, mainly through enzymatic antioxidants which block the harmful effects of ROS. These free radicals are neutralized by antioxidants, which gained more importance due to their ability to scavenge the free radicals before causing damage in body cells. Antioxidants have ability to reduce the oxidative stress and prevent the oxidative damage. Naturally occurring antioxidant compounds have been identified as free radical scavengers. Various medicinal and herbal plants are serving as a chief source for potent antioxidants [1]. Secondary metabolites of the plants such as carotenoids, flavonoids and related polyphenols forms buffering systems to counteract excessively generated free radicals in every cell [2]. They exhibited a significant biological role due to their antioxidant activity [3, 4].

A group of antioxidant enzymes includes superoxide dismutase (SOD), catalase (CAT) that act as a major defense to deactivate the $\operatorname{ROS}[5,6]$. Many phytochemicals isolated from plants up-regulated the antioxidant enzymes and thereby scavenge ROS produced in the body. Numerous in vitro and in vivo studies shown that plant extracts and their constituents such as polyphenols and its derivatives, flavonoids, glycosides, alkaloids, saponins, peptidoglycans, minerals, and vitamins protect cells from oxidative damage directly through free radical scavenging activities or indirectly by modulating signal transduction pathways and expression of redox-related genes [7,8]. Lipid peroxidation is also a well-known mechanism of cellular injury and therefore it is treated as an indicator of oxidative stress in cells and tissues. Asparagus racemosus is known to have a wide range of chemical constituents such as saponins, alkaloids, and tannins [9]. Roots are richest source of steroidal saponins showing different properties and thus find numerous pharmacological uses $[10,11]$. The major steroidal saponins in the roots are Shatavarins (I-IV) [12,13], and though, saponins possess a variety of biological properties, namely, being antioxidants, immunostimulants, antihepatotoxic, antibacterial, useful in diabetic retinopathy, anticarcinogenic, antidiarrheal, antiulcerogenic, antioxytocic, and reproductive agents [14]. The efficacy of these compounds against oxidative stress has not been studied so far. In the present study we have analyzed the major antioxidant enzymes such as SOD, CAT and 
$\mathrm{G}_{6} \mathrm{PD}$ as well as LPO to know the efficacy of ShathavariIV in Drosophila melanogaster against the oxidative stress.

\section{MATERIAL AND METHODS}

\subsection{Chemicals}

Paraquat dichloride, Methionine, EDTA, Nitro blue tetrazolium (NBT), Hydrogen peroxide, Nicotinamide adenine dinucleotide phosphate (NADP), Trichloroacetic acid (TCA), Reduced glutathione, 5, 5'- dithio-bi's (2nitrobenzoic acid) (DTNB), Bovine serum albumin (BSA) were procured from Sigma Aldrich, India. All the chemicals used were of analytical grade (AR).

\subsection{Isoalation of Shathavari-IV}

Shathavari-IV (Shr-IV) was isolated from the roots of Asparagus racemosus plant which were collected in and around Mysore district, Karnataka, India. The plant Asparagus racemosus (lilliacea) was authenticated by Curator, Mahatma Gandhi Botanical Garden, GKVK, Bangalore with the Acc no UASB-5398. The collected roots were washed and dried in the laboratory under shade at room temperature and powdered using an electric blender. The powder of plant was subjected to ethanolic extraction by using Soxhlet extraction unit, thus obtained extract was subjected to HPLC for purification and isolation. The purified steroidal saponin Shathavari IV (Shr-IV) confirmed by GC_MS analysis and the same is used for in vivo studies.

\subsection{Culturing of flies}

Drosophila melanogaster, wild stocks of strain Oregan K were obtained from Drosophila Stock Center, Department of Zoology, Manasagangothri, University of Mysore, Mysore, Karnataka. The flies were cultured in a standard wheat cream agar media seeded with yeast granules and maintained at $22 \pm 1^{\circ} \mathrm{C}$ of relative humidity $70-80 \%$. All the biochemical experiments were carried out in synchronized flies used from isofemale line stocks. Synchronized eggs were collected from the Delcour technique as per the standard procedure [15]. Newly eclosed flies were segregated under mild anesthesia and then, flies were maintained in Shr-IV supplemented culture media and aged them for 30, 45 and 60 days.

\subsection{Stress induction by Paraquat (PQ) Exposure}

To fix the lethal dose of PQ, flies were transferred to the vials containing filter paper soaked with $5 \%$ sucrose solution and various concentrations such as 30, 40 and $50 \mathrm{mM}$ of PQ, and exposed for 24-120 hrs. for the observation of lethality. Based on $\mathrm{LD}_{50}$ value, $20 \mathrm{Mm}$ of PQ was fixed for further stress induction analysis. Different age grouped (30, 45, 60 days) Shr-IV supplemented flies were starved in empty vials of size $8.5 \mathrm{x} 3 \mathrm{~cm}$ for $2 \mathrm{hrs}$. Then flies were exposed $20 \mathrm{mM}$ PQ in $5 \%$ sucrose solution through a soaked filter paper for $24 \mathrm{hrs}$. The control group received only 5\% sucrose solution. Survival was determined after $24 \mathrm{hrs}$ and survived flies were used for homogenization for biochemical assays. Each assay was repeated thrice. 50 flies were maintained in each batch (10flies/vial).

\subsection{Antioxidant enzyme assay}

All the antioxidant enzyme (SOD, CAT $\mathrm{G}_{6} \mathrm{PD}$ ) activities and lipid peroxidation were measured in the Shr-IV supplemented flies with two different concentrations (dose I- $1 \mathrm{mg} / \mathrm{ml}$ and dose II- $10 \mathrm{mg} / \mathrm{ml}$ ) at different age groups (30, 45 and 60 days). All the experiments were carried out in both stressed and non-stressed conditions. The extract treated with oxidative stress molecule (PQ) induced flies were considered as stressed group and the extract treated without OS induced flies were considered as non-stressed group.

\subsection{Superoxide dismutase enzyme (SOD)}

SOD activity was measured as per the standard procedure [16]. Fly homogenate was used for the preparation of samples. $3 \mathrm{ml}$ mixture was prepared by adding phosphate buffer of $\mathrm{pH} 7.8,100 \mathrm{mM}$ methionine, $10 \mathrm{mM}$ riboflavin, $5 \mathrm{mM}$ EDTA, $750 \mathrm{mM}$ NBT and enzyme extract with distilled water. The reaction mixture was gently mixed and incubated in dark at 400W bulbs for 15 minutes. Absorbance was measured at $560 \mathrm{~nm}$ in a UV spectrophotometer against blank. SOD activity was calculated per mg of protein.

\subsection{Catalase (CAT)}

The catalase activity was conducted by following the standard protocols [17]. $100 \mu \mathrm{l}$ of fly homogenate was added to a mixture of phosphate buffer and $100 \mu \mathrm{l}$ of hydrogen peroxide and the absorbance was read at 240 $\mathrm{nm}$ in a UV spectrophotometer. Catalase activity was calculated using the following formula:

Units $/ \mathrm{ml}$ of enzyme $=\Delta \mathrm{A}(\mathrm{min}) /(\mathrm{E} \times \mathrm{mg}$ of protein $)$ $=\mu \mathrm{m} \mathrm{H}_{2} \mathrm{O}_{2}$ Consumed $/ \mathrm{min} / \mathrm{mg}$ of protein

\subsection{Glucose- 6 -phosphate dehydrogenase

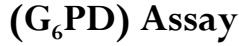

The total activity of $\mathrm{G}_{6} \mathrm{PD}$ was measured in Shr-IV supplemented flies by following the modified method [18]. $100 \mu \mathrm{l}$ of supernatant was mixed with $0.4 \mathrm{ml}$ of 
1.5M Tris HCL (pH7.5) containing $3.8 \times 10^{-4} \mathrm{M}$ NADP, $0.01 \mathrm{ml}$ of $0.3 \mathrm{M} \mathrm{MgCl}_{2}$ and $0.5 \mathrm{ml}$ of $0.03 \mathrm{M} \mathrm{D}$ glucose 6 phosphate. The activity of the reaction mixture was measured at one minute interval for 3 minutes at $340 \mathrm{~nm}$ using UV spectrophotometer. The activity was calculated based on molar extinction coefficient $6.22 \mathrm{mM}^{-1} \mathrm{~cm}^{-1}$

\subsection{Lipid peroxidation assay}

Lipid Peroxidation assay was measured by employing thiobarbituric acid (TBA) as per the standard procedure [19]. Assay was carried out in different aged fly groups. The reaction mixture consisted of $0.2 \mu \mathrm{l}$ of homogenate sample, $0.2 \mu \mathrm{l}$ of SDS $(8.1 \% \mathrm{w} / \mathrm{v}), 1.5 \mathrm{ml}$ of acetic acid $(\mathrm{pH} 3.5,20 \%), 1.5 \mathrm{ml}$ of TBA $(0.8 \% \mathrm{w} / \mathrm{v})$ and reaction mixture was made up to $4 \mathrm{ml}$ with distilled water, mixed well. The mixture was incubated in a water bath at $90^{\circ} \mathrm{C}$ for $60 \mathrm{~min}$. and then cooled in icebath. After cooling, samples were mixed with $3 \mathrm{ml}$ of n-butanol and centrifuged at $5000 \mathrm{rpm}$ for $10 \mathrm{~min}$. Further, supernatant was carefully transformed to another test tube and the absorbance was measured at $532 \mathrm{~nm}$. Lipid peroxidation was quantified as malondialdehyde (MDA) equivalents using 1,1,3,3tetramethoxypropane as the standard (molar extinction coefficient value is $15600 \mathrm{M}^{-1} \mathrm{~cm}^{-1}$ ). Blank solution was prepared by mixing all the reagents except sample homogenate.

\subsection{Determination of total protein}

The total quantity of protein in whole body homogenates prepared from Shr-IV supplemented flies were measured as per standard protocol [20]. Estimation was carried out by taking BSA as standard. The quantity of protein was estimated through standard graph.

\subsection{STATISTICAL ANALYSIS}

Data were expressed as mean \pm SE for all the enzyme activities. To know the level of significance among the groups in all analyzed studies, data were subjected to one way ANOVA analysis individually using SPSS software of version 16.0. To detect the significant levels between control and bioactive compound supplemented batch flies with doses, data were further subjected to DMRT. A probability of $\mathrm{P}<0.05$ was considered as significant.

\section{RESULTS AND DISCUSSION}

First lines of defense against oxidative stress on the body are the endogenous antioxidants. The major endogenous antioxidants are enzymes that play an important role in lowering the reactive oxygen species (ROS) levels and reduce the oxidative stress. The actions of ROS in the cells are minimized through the action of the SOD enzyme activity which facilitates the conversion of superoxide anion to less damaging compounds that are then converted to water by the action of catalase. The antioxidant enzymes capable of scavenging ROS are SOD, CAT and $\mathrm{G}_{6} \mathrm{PD}$ and considered them as biomarkers of oxidative stress [21].

The dietary supplementation with curcumin of Curcuma longa increase antioxidant enzymes in $D$. melanogaster [22]. Apple polyphenols, green tea catechins increases SOD, CAT and GPx enzyme levels in D. melanogaster, which in turn neutralized the free radicals [23-25]. Since superoxide is the primary ROS produced from a variety of sources, it is dismutated by SOD in each cell. SODs are first line antioxidant defense by virtue of ability to convert highly reactive superoxide radicals into $\mathrm{H}_{2} \mathrm{O}_{2}$ and molecular oxygen [26]. Catalase is a tetra mericporphyrin-containing enzyme that is located mainly in peroxisomes. It catalyzes the conversion of $\mathrm{H}_{2} \mathrm{O}_{2}$ to water and molecular oxygen in two steps [27]. The Hydrogen peroxide $\left(\mathrm{H}_{2} \mathrm{O}_{2}\right)$ produced by the action of SOD is reduced to water by $\mathrm{CAT}$ and glutathione (GSH).

The major bioactive constituents of Asparagus are a group of steroidal saponins exists in the form of Shatavarin-IV. It is a glycoside of sarsasapogenin having two molecules of Asparagus rhamnose and one molecule of glucose. In the present analysis, the compound Shr-IV was screened for invivo radical scavenging activity. All the antioxidant enzyme activities and LPO activities were measured in Shr-IV fed flies of D. melanogaster. Paraquat is a good measure of free radical scavenging activity [28], hence activities were also measured under stress conditions, using PQ as a stress molecule. All the three antioxidant enzymes were gradually increased from 30 days age grouped flies to 45 days aged flies in both stress and non stress conditions. The activity was declined at 60 days age grouped flies. The result of SOD activity was compiled in the Fig.1. The data reveals that SOD activity was maximum in both male (44.01 units/ $\mathrm{mg}$ of protein) and females (48.51 units $/ \mathrm{mg}$ of protein) at 45 days aged group. It increased by 1.3 folds in males and 1.4 folds in females under both stress and non stress states than control batches. However, 45 days aged control flies exhibited same enzyme activity as 60 day of ShrIV supplemented groups. Another important ROS-detoxifying enzyme is Catalase. The result of CAT activity was compiled in the 
Fig. 2. Similar to SOD, the data on CAT reveals that the enzyme activity was reached maximum at 45 days aged flies in Shr-IV fed batches in non stress state, males expressed 31.09 units/mg of protein, females expressed $33.31 \mathrm{units} / \mathrm{mg}$ of protein. Similar such result was also observed even under stress state. Shr-IV fed flies under non stress conditions increases the CAT activity by 1.15 folds in males, 1.12 folds in females than control group. However under stress conditions Shr-IV compound increases the CAT activity by 1.4 folds more in male flies, 1.24 folds more in female flies than control batch.

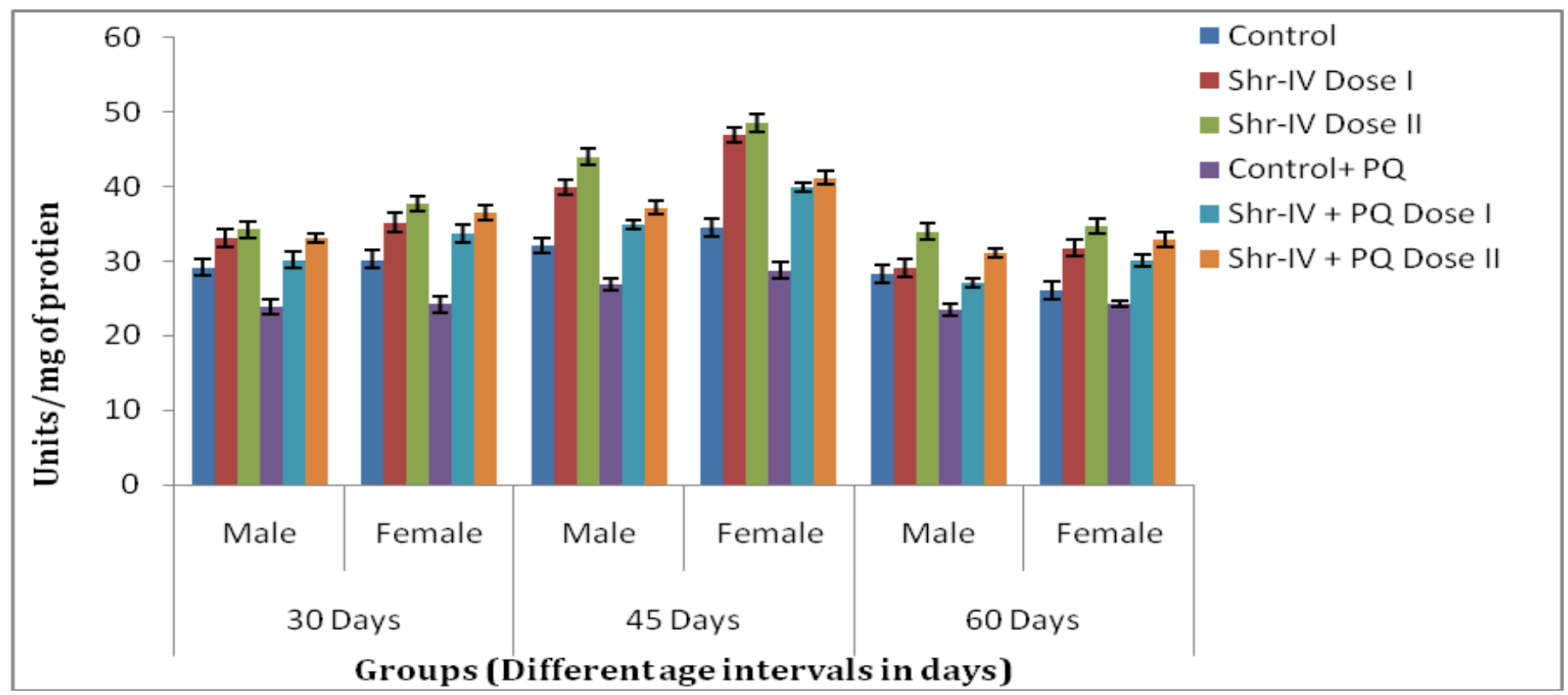

Error bar represents Mean $\pm S E$

Fig. 1: Effect of Shr-IV on SOD activity in different age grouped flies of $D$. melanogaster under stress and non stress conditions

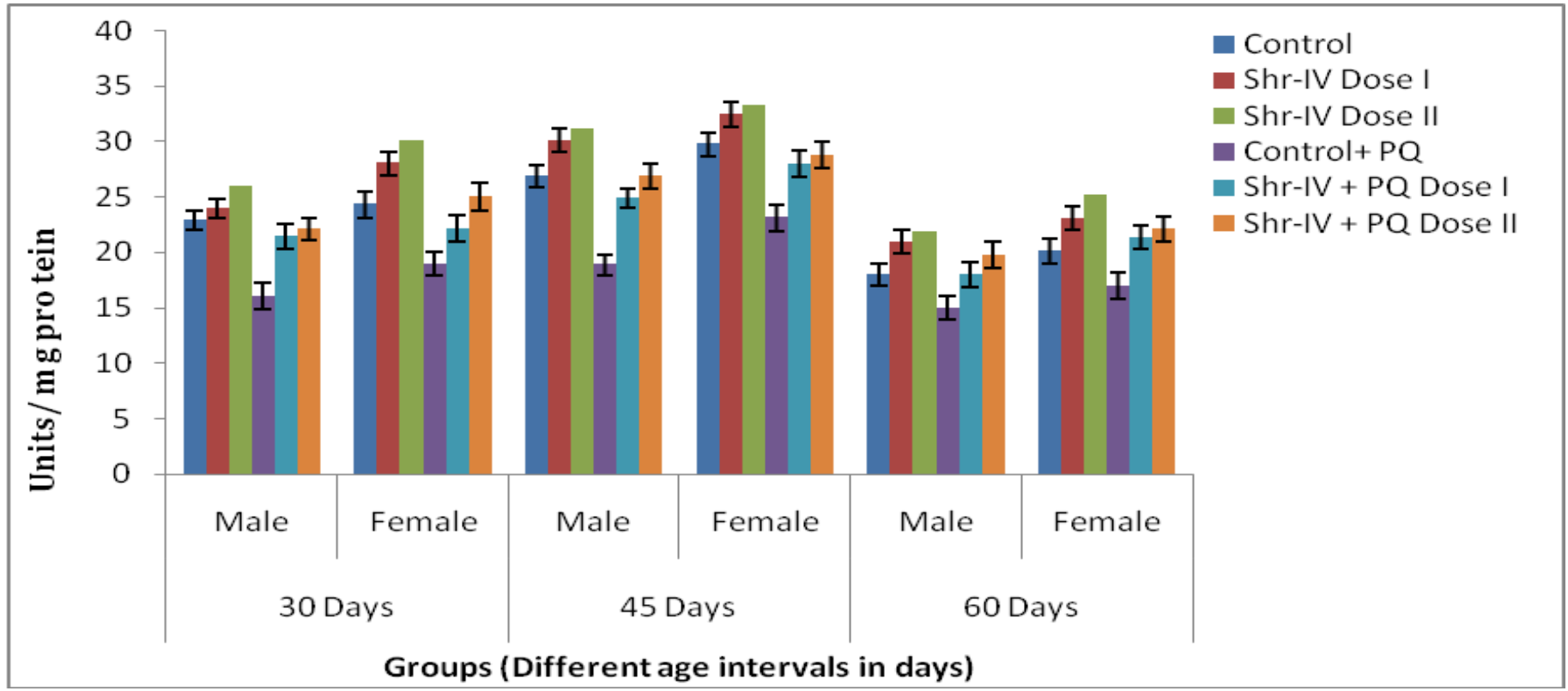

Error bar represents Mean $\pm S$

Fig. 2: Effect of Shr-IV on CAT activity in different age grouped flies D. melanogaster under stress and non stress conditions 
NADPH contributes to the maintenance of the active form of catalase, $\mathrm{G}_{6} \mathrm{PD}$ involved in the generation of NADPH which is the first enzyme of the pentose phosphate pathway [29]. $\mathrm{G}_{6} \mathrm{PD}$ improves ROS detoxification and thereby reduce the oxidative stress. Over expression of $\mathrm{G}_{6} \mathrm{PD}$ in Drosophila melanogaster protects against oxidative stress and can extend lifespan [30]. The result of $\mathrm{G}_{6} \mathrm{PD}$ activity of all the analyzed groups was compiled in the Fig. 3 which was expressed as unit/mg protein. The maximum enzyme activity was observed in 45 days aged group flies in non stress and (0.053 units in male and 0.061 units in female) and under stress conditions (0.044 units in male and 0.051 units in female) that increased by 1.2 folds than control batches.

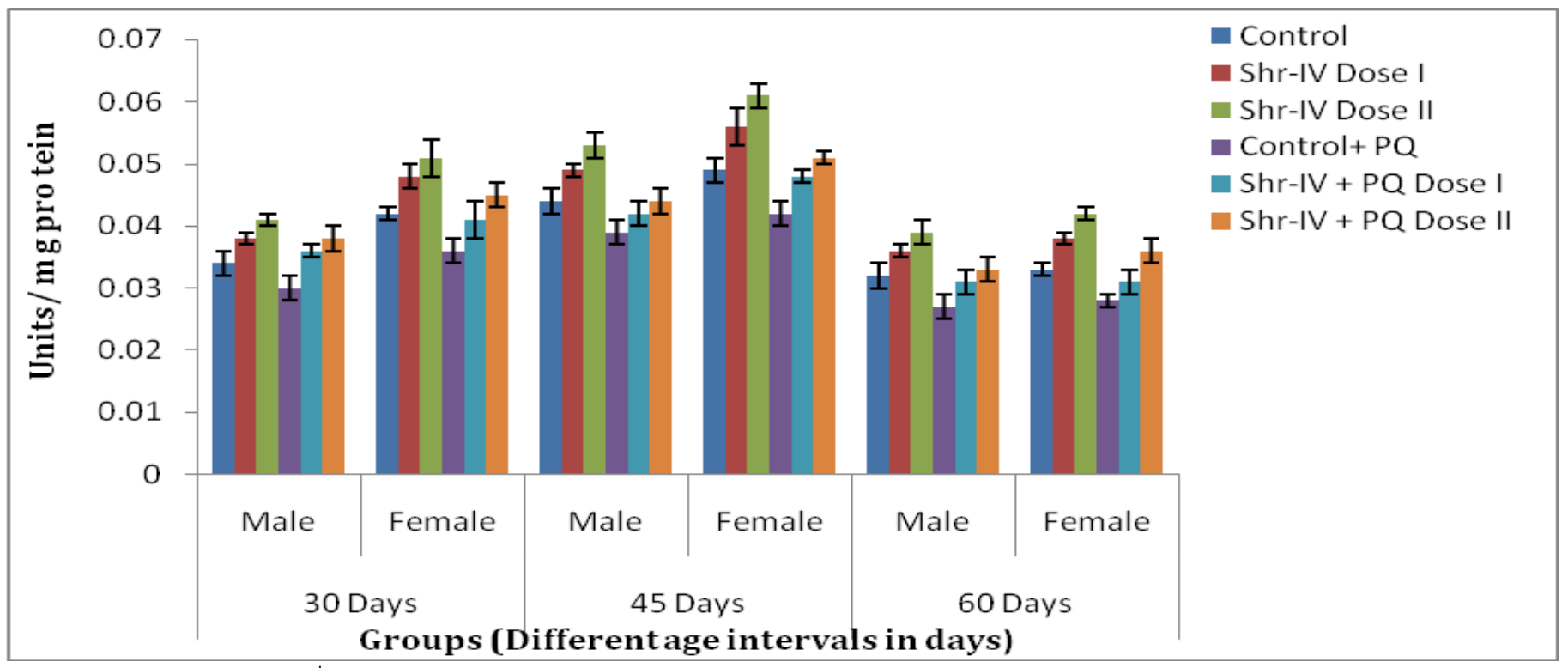

Error bar represents Mean $\pm S E$

Fig. 3: Effect of Shr-IV on $\mathbf{G}_{6} P D$ activity in different age grouped flies $D$. melanogaster under stress and non stress conditions

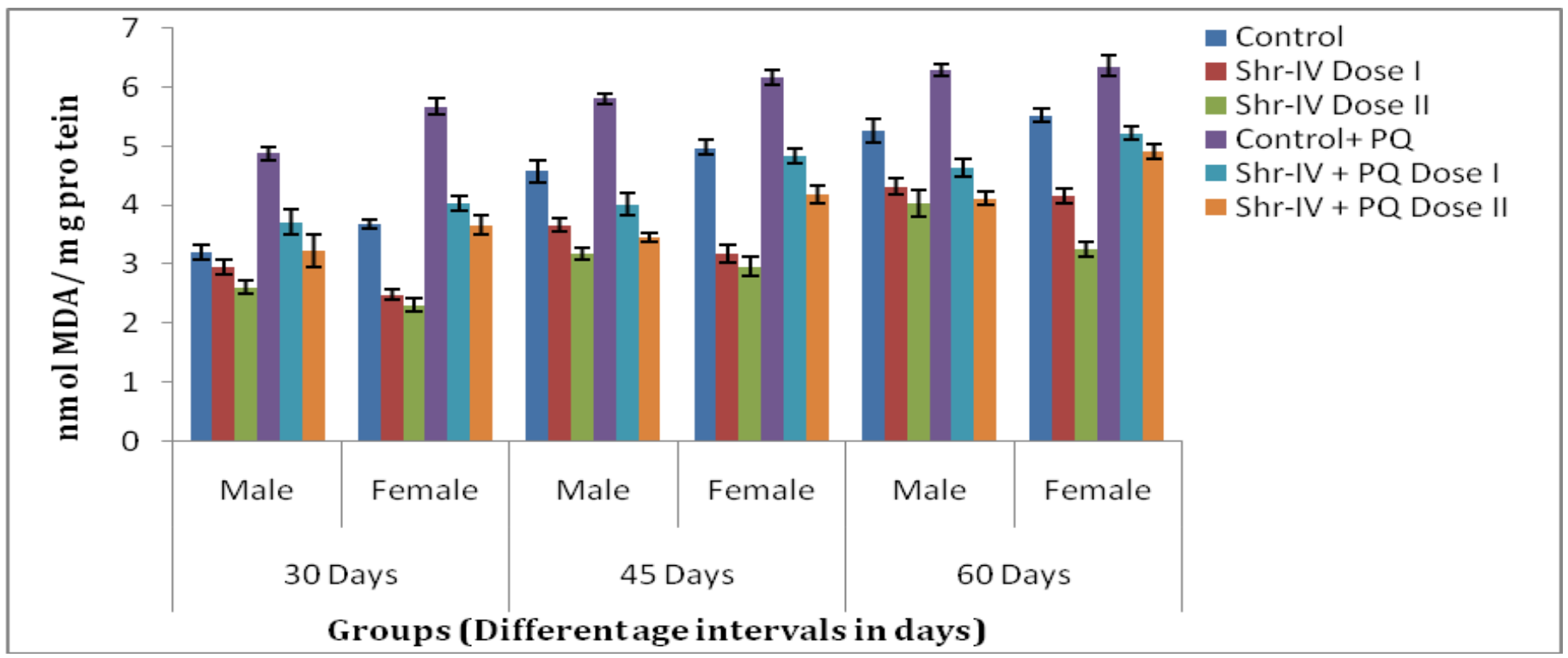

Error bar represents Mean $\pm S E$

Fig. 4: Effect of Shr-IV on LPO activity in different age grouped flies $D$. melanogaster under stress and non stress conditions. 
Lipid peroxidation is the chain of reactions of oxidative degradation of lipids where free radicals "steal" electrons from the lipids in cell membranes, resulting in cell damage; hence measurement of LPO is chief marker for the indication of oxidative stress. It is measured through MDA activity per mg protein. The data as shown in the Fig.4, the LPO activity was increased as fly ages under non stressed and stressed conditions, maximum activity was observed at 60 days flies. The control without PQ induced group expressed 5.26 units of activity in male group, 5.53 units of activity in female group, while the control with PQ induced group (in male and female) expressed 6.29 units and 6.36 units of activity, respectively. However, the LPO activity was decreased in Shr-IV fed groups; it was decreased 1.3 folds under nonstressed and 1.42 folds under stressed conditions. Further, it shows that dose II batch of Shr-IV supplemented flies exhibited more enzyme activities when compared to dose-I batch and female flies expressed more enzyme activity than male flies. Pre-fed with Shr-IV compound in Drosophila significantly increases the synthesis of SOD, CAT and $\mathrm{G}_{6} \mathrm{PD}$. Similar observation was reported earlier in flies where fed with green tea extract and Phyllanthus extract and opined that the antioxidant rich plant extracts elevated SOD and CAT activities in Drosophila by reducing LPO [24,31]. Further, the present result observed that 60 days aged Shr-IV pre fed flies expressed SOD and CAT activity which was equal to 45 days of control flies, that indicates Shr-IV compound is responsible for maintaining the enzyme activity even in aged flies.

PQ induced control flies also showed significant elevation of antioxidant enzymes. Interestingly, Shr-IV pre fed flies with the exposure of PQ showed significant increase of antioxidant enzymes. These result suggested that the Shr-IV compound could scavenge the free radicals by increasing all these antioxidant enzyme activity. PQ induced flies showed significant elevation of LPO; this evidences the occurrence of oxidative stress after PQ exposure. The supplementation of ShrIV in different age grouped flies suppresses the PQ induced oxidative stress with reduction of LPO. These findings fall in line of studies of [24] and others as well as [31]. As Shr-IV is a major bioactive compound of Asparagus racemosus, its medicinal properties has been proved [12, 32], present investigation proves the antistress property through antioxidant enzyme analysis against PQ.

\section{CONCLUSION}

In conclusion, the studies reveal that the supplementation of Shr-IV a steroidal saponin of Asparagus racemosus increases the SOD and CAT and $\mathrm{G}_{6} \mathrm{PD}$ activities in D. melanogaster even under stressed conditions. Shr-IV fed flies also decreases the LPO (MDA) significantly even after paraquat expose. Hence, Shr-IV minimizes the oxidative stress and proves its antistress property. Since our investigation justified that Shr-IV of A. racemosus is a rich source of antioxidant compounds. The antioxidant property of Shr-IV in Drosophila melanogaster in the current study has provided the base line data for further experiments in human being.

\section{REFERENCES}

1. Parisa S, Reza H, Elham G, Rashid J. Pakistan J. Biol. Sci, 2010; 10:267-272.

2. Devasagayam TPA, Tilak JC, Boloor KK, Sane KS, Ghaskadbi SS, Lele RD. Japi, 2004; 52:794-804.

3. Agati G, Matteini P, Goti A, Tattini M. New Phytologist, 2007; 174(1):77-89.

4. Huda Faujan N, Noriham A, Norrakiah A S, Babji A S. African Journal of Biotechnology, 2009; 8(3).

5. Beyer W, Imlay J, Fridovich I. Progress in nucleic acid research and molecular biology, 1991; 40:221-253.

6. Matés JM, Pérez Gómez C, De Castro IN. Clinical biochemistry, 1999; 32(8):595-603.

7. Bharti SK, Krishnan S, Kumar A, Kumar A. Therapeutic Advances in Endocrinology and metabolism, 2018; 9(3):81-100.

8. Unuofin JO, Lebelo SL. Oxidative medicine and cellular longevity, 2020.

9. Zhang H, Birch J, Pei J, Ma ZF, Bekhit AED. International Journal of Food Science \& Technology, 2019; 54(4):966-977.

10. Joshi RK. Inter. J. Herb. Med, 2016; 4(4):18-21.

11. Saran PL, Singh S, Solanki VH, Devi G, Kansara RV, Manivel P. Heliyon, 2020; 6(12):56-74.

12. Kamat JP, Boloor KK, Devasagayam TP, Venkatachalam SR. Journal of ethnopharmacology, 2000; 71(3):425-435.

13. Thakur S, Sharma DR. Int. J. Pharm Sci Health Care, 2015; (5):82-97.

14. Negi JS, Singh P, Joshi GP, Rawat MS, Bisht VK. Pharmacognosy Reviews, 2010; 4(8):215.

15. Ramachandra NB, Ranganath HA. Genome, 1988; 30:58

16. Beyer JR, Fridovich I. Analytical biochemistry, 1987; 161(2):559-566. 
17. Aeibi H, Bergmeyer H. New York, Academic Press, 1974; 3:673.

18. Kumar, Saritha, Thomas A, Pillai M K. Indian journal of experimental biology, 1991; 29(4):379-384.

19. Buege JA, Aust SD. Academic press, 1978; 52:302310 .

20. Lowry OH, Rosebrough NJ, Farr AL, Randall RJ. Journal of biological chemistry, 1951; 193:265-275.

21. Osawa T, Sugiyama Y, Inayoshi M, Kawakishi S. Bioscience biotechnology and biochemistry, 1995; 59(9):1609-1612.

22. Akinyemi AJ, Oboh G, Ogunsuyi O, Abolaji AO, Udofia A. Metabolic brain disease, 2018; 33(2):369375 .

23. Reddy ACP, Lokesh BR. Molecular and cellular biochemistry, 1992; 111(1):117-124.

24. Li-Rong Shen, Fa Xiao, Peng Yuan, Ying Chen, Qi,Kang Gao, Laurence D Parnell, et al. Age,
2013; 35:1133-1142.

25. Peng C, Chan HYE, Huang Y, Yu H, Chen ZY. Journal of agricultural and food chemistry, 2011; 59(5):2097-2106.

26. Wang W, Xia MX, Chen J, Yuan R, Deng FN, Shen FF. Biochemistry (Moscow), 2016; 81(5): 465-480.

27. Aslani BA, Ghobadi S. Life sciences, 2016; 146:163173.

28. Phillips JP, Campbell SD, Michaud D, Charbonneau M, Hilliker AJ. Proceedings of the National Academy of Sciences, 1989; 86(8):2761-2765.

29. Hillar A, Nicholls PA. FEBS Lett, 1992; 314:179. 182.

30. Legan SK, Rebrin I, Mockett RJ, Radyuk SN, Klichko VI, Sohal RS, Orr WC. Journal of Biological Chemistry, 2008; 283(47):32492-32499.

31. Manasa N, Ashadevi JS. J. Appl. Biol. Biotechnology, 2015; 3(6):043-047 